\title{
Association between prior cardiometabolic therapy and in-hospital mortality in very old patients with type 2 diabetes mellitus hospitalized due to COVID- 19. A nationwide observational study in Spain
}

Jose Manuel Ramos-Rincón

Miguel Hernandez University of Elche: Universidad Miguel Hernandez de Elche

Luis M Pérez-Belmonte ( $\sim$ luismiguelpb1984@gmail.com )

Hospital Regional Universitario de Málaga: Hospital Regional Universitario de Malaga

https://orcid.org/0000-0001-9512-8274

Francisco Javier Carrasco-Sánchez

Hospital Juan Ramón Jiménez: Hospital Juan Ramon Jimenez

Sergio Jansen-Chaparro

Hospital Regional Universitario de Málaga: Hospital Regional Universitario de Malaga

Mercedes De-Sousa-Baena

Hospital Juan Ramón Jiménez: Hospital Juan Ramon Jimenez

José Bueno-Fonseca

Hospital Regional Universitario de Málaga: Hospital Regional Universitario de Malaga

Maria Pérez-Aguilar

Hospital Juan Ramón Jiménez: Hospital Juan Ramon Jimenez

Coral Arévalo Cañas

Hospital 12 de Octubre Servicio de Medicina Interna

Marta Bacete Cebrian

Hospital General Universitario Gregorio Marañón: Hospital General Universitario Gregorio Maranon

Manuel Méndez-Bailón

San Carlos University Hospital Internal Medicine III Service: Hospital Clinico Universitario San Carlos

Servicio de Medicina Interna III

Isabel Fiteni Mera

Royo Villanova Hospital: Hospital Royo Villanova

Andrés González García

Hospital Ramon y Cajal: Hospital Universitario Ramon y Cajal

Francisco Navarro Romero

Hospital Costa del Sol

Carlota Tuñón de Almeida

: Complejo Asistencial de Zamora 


\section{Gemma Muñiz Nicolás}

Hospital Virgen de la Salud

\section{Amara González Noya}

Complejo Hospitalario de Orense: Complexo Hospitalario de Ourense

Almudena Hernández Milian

Hospital Universitario Son Espases: Hospital Universitari Son Espases

\section{Gema María García García}

Complejo Hospitalario Universitario de Badajoz

José Nicolás Alcalá Pedrajas

VS Hospital

\section{Virginia Herrero García}

Hospital Doctor Jose Molina Orosa

\section{Luis Corral-Gudino}

Hospital Universitario Rio Hortega

\section{Pere Comas Casanova}

Hospital de Blanes

Héctor Meijide Míguez

Hospital QuironSalud A Coruña

José Manuel Casas-Rojo

Hospital Universitario Infanta Cristina

Ricardo Gómez-Huelgas

Regional University Hospital of Malaga: Hospital Regional Universitario de Malaga

\section{Original investigation}

Keywords: coronavirus disease-2019, older patient, type 2 diabetes mellitus, in-hospital mortality, cardiometabolic therapy

Posted Date: December 28th, 2020

DOl: https://doi.org/10.21203/rs.3.rs-133358/v1

License: (c) (1) This work is licensed under a Creative Commons Attribution 4.0 International License. Read Full License 


\section{Abstract \\ Background}

Advanced age and diabetes are both associated with poor prognosis in COVID-19. However, the effects of cardiometabolic drugs on the prognosis of diabetic patients with COVID-19, especially very old patients, are not well-known. This work aims to analyze the association between preadmission cardiometabolic therapy (antidiabetic, antiaggregant, antihypertensive, and lipid-lowering drugs) and in-hospital mortality among patients $\geq 80$ years with type 2 diabetes mellitus hospitalized for COVID-19.

\section{Methods}

We conducted a nationwide, multicenter, retrospective, observational study in patients $\geq 80$ years with type 2 diabetes mellitus and COVID-19 hospitalized in 160 Spanish hospitals between March 1 and May 29, 2020 who were included in the SEMI-COVID-19 Registry. The primary outcome measure was inhospital mortality. A multivariate logistic regression analysis were performed to assess the association between preadmission cardiometabolic therapy and in-hospital mortality. The regression analysis values were expressed as adjusted odds ratios (AOR) with a 95\% confidence interval (Cl). In order to select the variables, the forward selection Wald statistic was used. Discrimination of the fitted logistic model was assessed via a receiver operating characteristic (ROC) curve. The Hosmer-Lemeshow test for logistic regression was used to determine the model's goodness of fit.

\section{Results}

Of the 2,763 patients $\geq 80$ years old hospitalized due to COVID-19, $790(28.6 \%)$ had T2DM. Of these patients, 385 (48.7\%) died during admission. On the multivariate analysis, the use of dipeptidyl peptidase4 inhibitors (AOR 0.502, 95\% Cl 0.309-0.815, $\mathrm{p}=0.005$ ) and angiotensin receptor blockers (AOR 0.454, $95 \% \mathrm{Cl} 0.274-0.759, \mathrm{p}=0.003$ ) were independent protectors against in-hospital mortality whereas the use of acetylsalicylic acid was associated with higher in-hospital mortality (AOR 1.761, 95\% Cl 1.092$2.842, p=0.020$ ). Other antidiabetic drugs, angiotensin-converting enzyme inhibitors and statins showed neutral association with in-hospital mortality. The model showed an area under the curve of 0.788 .

\section{Conclusions}

We found important differences between cardiometabolic drugs and in-hospital mortality in older patients with type 2 diabetes mellitus hospitalized for COVID-19. Preadmission treatment with dipeptidyl peptidase- 4 inhibitors and angiotensin receptor blockers may reduce in-hospital mortality; other antidiabetic drugs, angiotensin-converting enzyme inhibitors and statins seem to have a neutral effect; and acetylsalicylic acid may be associated with excess mortality. 


\section{Background}

Aging is one of the most significant factors associated with a poor prognosis in coronavirus disease2019 (COVID-19) [1-4]. In addition, diabetes is a common comorbidity among patients with severe COVID-19 $[5,6]$ and while it does not increase susceptibility to severe acute respiratory syndrome coronavirus 2 (SARS-CoV-2) infection, it has also been correlated with a more severe course of COVID-19 $[7,8]$.

As expectations of specific antiviral and immunological therapies for the management of COVID-19 have dimmed [9], drugs used for controlling cardiovascular risk factors have emerged as having a potentially important role in the approach to patients with COVID-19. In this sense, some studies have suggested possible protective effects of angiotensin-converting enzyme inhibitors (ACEI) or angiotensin II receptor blockers (ARB) [10, 11], statins [12, 13], acetylsalicylic acid (ASA) [14], dipeptidyl peptidase-4 inhibitors (DPP-4i) [15], and metformin [16], although these findings are based on observational studies and their conclusions are controversial $[3,17-19]$.

Our aim was to analyze the association between preadmission cardiometabolic therapy (antidiabetic, antiaggregant, antihypertensive, and lipid-lowering drugs) with in-hospital mortality in patients $\geq 80$ years with type 2 diabetes mellitus (T2DM) hospitalized due to COVID-19.

\section{Material And Methods}

\section{Study Design and Population}

We conducted an observational, multicenter, nationwide study of patients $\geq 80$ years of age with T2DM hospitalized with COVID-19 in Spain from March 1 to May 29, 2020. All patient data was obtained from the Spanish Society of Internal Medicine's SEMI-COVID-19 Registry, in which 160 hospitals in Spain participate. The SEMI-COVID-19 Registry retrospectively compiles data on the first admission of patients $\geq 18$ years of age with COVID-19 confirmed microbiologically by a reverse transcription polymerase chain reaction (RT-PCR) test. More in-depth information on the justification, objectives, methodology, and preliminary results of the SEMI-COVID-19 Registry have recently been published [6].

\section{Definition of variables}

Patients were considered to have T2DM if this diagnosis was recorded on their electronic medical record and they were treated with antidiabetic drugs. We analyzed the use of antidiabetic drugs (metformin, DPP-4i, insulin, sodium-glucose cotransporter 2 inhibitors (SGLT-2i) and glucagon-like peptide-1 receptor agonist (GLP-1 ra), antiaggregant drugs (ASA), antihypertensive drugs (ACEI, ARB), and statins. All preadmission comorbidities were collected from patients' electronic medical records, which were obtained from each hospital. In-hospital mortality was the primary outcome variable. More in-depth information about the definition of other variables has recently been reported in manuscripts published by the SEMICOVID-19 Network $[4,6]$. 


\section{Statistical analysis}

Patients were divided into two groups: survivors and non-survivors. The characteristics of each group were analyzed using descriptive statistics. Continuous and categorical variables were expressed as medians and interquartile ranges (IQR) and as absolute values and percentages, respectively. The differences between groups were calculated using the Mann-Whitney $U$ test for continuous variables and Pearson's chi-square test for categorical variables. Values were considered to be statistically significant when $\mathrm{p}<0.05$.

A multivariate analysis was performed to control for confounding variables. The regression analysis values were expressed as adjusted odds ratios (AOR) with a 95\% confidence interval (Cl). A multiple logistic regression analysis was used to identify independent variables of in-hospital mortality. In order to select the variables, the forward selection Wald statistic was used. Variables analyzed in the model were: demographics (age, sex, acquisition), comorbidities and dependence (degree of dependence, Charlson Comorbidity Index, hypertension, dyslipidemia, coronary disease, cerebrovascular disease, peripheral vascular disease, atrial fibrillation, heart failure, dementia, chronic lung disease, obesity, malignancy, moderate-to-severe renal disease), symptoms (dyspnea), physical examination (oxygen saturation $<90 \%$, temperature $37.8^{\circ} \mathrm{C}$, tachycardia, quick sequential organ failure assessment score $\geq 2$ ), laboratory findings (neutrophils, lymphocytes, hemoglobin, platelet count, glucose, estimated glomerular filtration rate, lactate dehydrogenase, c-reactive protein, alanine aminotransferase), and treatment (metformin, DPP-4i, insulin, SGLT-2i, GLP-1ra, ASA, ACEI, ARB and statin). Discrimination of the fitted logistic model was assessed via a receiver operating characteristic (ROC) curve. The Hosmer-Lemeshow test for logistic regression was used to determine the model's goodness of fit. Due to the fact that there were some missing values, variables which were not recorded for $>25 \%$ of patients were excluded from the analysis. These included serum ferritin, D-dimer, interleukin-6, procalcitonin, venous lactate, and aspartate aminotransferase. Statistical data analysis was performed using IBM SPSS Statistics for Windows, Version 22.0 (Armonk, NY: IBM Corp).

\section{Results}

\section{Baseline clinical characteristics, presentation, and laboratory data}

Of the 2,763 patients ${ }^{3} 80$ years old analyzed, 790 (28.6\%) had T2DM. Figure 1 shows the patient inclusion flowchart for this study. A total of 385 patients (48.7\%) died during admission. Baseline clinical characteristics, clinical presentation, and laboratory data of patients grouped by non-survivors and survivors are shown in Table 1. The percentages of females in the non-survivor and survivor groups were $43.2 \%$ and $51.0 \%$, respectively $(p=0.03)$. The percentages of patients with moderate and severe dependency in the non-survivor group were higher than in the survivor group $(52.6 \%$ vs. $44.8 \%, p<0.001)$. The median Charlson Comorbidity Index value and prevalence of comorbidities were similar in the survivor and non-survivor groups, with the exception of dementia ( $37.9 \%$ vs $30.2 \%, p=0.03)$. The presence of dyspnea, pulse oximetry $<90 \%$, fever, tachycardia, and qSOFA ${ }^{3} 2$ were more common in the non- 
survivor group. In terms of laboratory values, a higher proportion of patients in the non-survivor group had high admission values of leukocytes, neutrophils, plasma glucose, lactate dehydrogenase, aminotransferases, C-reactive protein, lactate, procalcitonin, ferritin, and D-dimer $(p<0.05)$ and low estimated glomerular filtration rate (eGFR) and lymphocyte values.

\section{Preadmission cardiometabolic therapy}

Preadmission cardiometabolic therapy of patients grouped by non-survivors and survivors is shown in Table 2. The antidiabetic drugs used before admission were similar between the non-survivor and survivor groups except for DDP-4i, which were used in $28.9 \%$ of non-survivors and $36.2 \%$ of survivors $(p=0.03)$. Statin and ARB use were less frequent in non-survivors than in survivors $(49.2 \%$ and $7.1 \%$ versus $56.6 \%$ and $19.8 \%$, respectively, $\mathrm{p}<0.05$ ) while the use of antiaggregants was similar in both groups.

\section{Associations between preadmission cardiometabolic drugs and in-hospital mortality}

On the multivariate analysis, the preadmission cardiometabolic medications found to be independent protective factors against in-hospital mortality were the use of DPP-4i (AOR 0.502, 95\% Cl 0.309-0.815, $p=0.005$ ) and ARB (AOR 0.454, 95\% $\mathrm{Cl} 0.274-0.759, p=0.003$ ) while the use of ASA was associated with greater in-hospital mortality (AOR 1.761, 95\% Cl 1.092-2.842, $\mathrm{p}=0.020$ ). Metformin (AOR 0.976, 95\% Cl 0.639-1.788, $p=0.792$ ), insulin (AOR 1.308, 95\% Cl 0.679-2.476, $p=0.576)$, SGLT-2i (AOR 0.812, 95\% Cl 0.755-1.988, $p=0.401$ ), GLP-1ra (AOR 0.912, 95\% Cl 0.501-1.896, $p=0.512$ ), ACEI (AOR 1.048, 95\% Cl 0.841-1.991, $p=0.186$ ), and statins (AOR $0.917,95 \% \mathrm{Cl} 0.723-1.978, p=0.335$ ) showed neutral association with in-hospital mortality. In this model, the goodness-of-fit showed a p-value of 0.142 (HosmerLemeshow test) and the area under the ROC curve was 0.788 (discrimination). Associations between preadmission cardiometabolic drugs and in-hospital mortality are shown in Table 3.

\section{Discussion}

The COVID-19 pandemic has affected older, frail individuals with diabetes particularly severely and there is still no effective treatment for COVID-19 available. Therefore, we performed a multicenter, nationwide, retrospective, observational study to analyze the impact of preadmission cardiometabolic medication on mortality in elderly diabetic patients hospitalized for COVID-19.

Our study suggests that preadmission treatment with DPP-4i and ARB could be associated with reduced in-hospital mortality in elderly patients with T2DM hospitalized for COVID-19 whereas treatment with ASA could be associated with excess mortality. Other antidiabetic drugs, ACEI, and statins showed neutral association with mortality.

So far, there has been no conclusive evidence in regard to the potential implications of cardiometabolic therapies on COVID-19 outcomes, especially among elderly patients. Additionally, whether certain antidiabetic drugs can improve the prognosis of diabetic patients with COVID-19 remains unknown. Studies on glucose-lowering drugs in patients hospitalized with COVID-19 have shown conflicting results. 
In some reports, the use of oral antidiabetics had a neutral effect on in-hospital mortality and the composite outcome of poor prognosis, defined as progression to severe or critical illness and in-hospital death $[19,20]$, whereas in other studies, metformin had a beneficial effect on clinical outcomes $[16,18]$. Insulin use was associated with a greater risk of poor prognosis compared to not using it $[20,21]$.

In our study, which was conducted solely in very old patients with T2DM, all antidiabetic therapies showed neutral effects on the clinical outcomes of COVID-19 with the notable exception of DPP-4i which, after exhaustive adjustment for potential confounding factors, were associated with a significant reduction in in-hospital deaths. Overall, data from human studies on the effects of DPP-4i in COVID-19 are scarce. Better clinical outcomes in patients with T2DM and COVID-19 have also been reported in a population-based study of 832 patients from the National Health Review and Assessment Service database in Korea [22].

In a recent multicenter, case-control, retrospective, observational study of 338 patients with T2DM admitted to hospitals in northern Italy for COVID-19, sitagliptin treatment in conjunction with insulin administration upon admission was determined to be associated with reduced mortality and improved clinical outcomes when compared to standard of care [15]. These potential benefits of DPP-4i in patients with T2DM and COVID-19 must be confirmed in further research and placebo-controlled trials. Currently, there are two ongoing trials analyzing the safety and efficacy of linagliptin in patients with T2DM hospitalized for COVID-19 (NCT04542213, NCT04371978).

Several possible mechanisms have been proposed to explain the potential benefits of DPP-4i in individuals with T2DM and COVID-19 [23-25]. First, T2DM is characterized by an overexpression of DPP4 receptors, thus their inhibition may have immunoregulatory and anti-inflammatory effects [26, 27]. Second, aging is associated with changes in cellular and humoral immunity that could favor worse outcomes in COVID-19 [28]. Third, DPP-4 has been identified as a receptor for MERS-CoV [22] and, additionally, the structure of SARS-CoV-2 spike glycoprotein S1, which mediates virus entry into the host cell, has high degree of homology with DPP-4 and angiotensin-converting enzyme 2 (ACE2) [29]. This may indicate that DPP-4 can facilitate SARS-CoV-2 entry into respiratory tract cells $[29,30]$ and as such, DPP-4 inhibition could contribute to reducing the viral load and improving inflammatory and immune responses so as to prevent a cytokine storm, which can entail lung injury and multiple organ failure in COVID-19 [31, 32].

A previous work from the SEMI-COVID-19 Network that analyzed 2,666 patients with T2DM admitted for COVID-19 did not find any significant associations between at-home glucose-lowering drugs and mortality or other adverse outcomes [19]. However, the mean age of patients in that study was much younger than those in our cohort (75 vs 86 years), a fact that could explain the difference in results. Aging may be associated with DPP-4 overexpression; a significant correlation between membrane DPP-4 activity and animal age has been found in murine models [33]. It has also been reported that DPP-4 receptor levels rise on the senescent cell surface, suggesting that DPP-4 could play an important role in the aging process [34]. Aging is also characterized by a state of chronic low-grade inflammation (termed 
"inflammaging") that could predispose patients to experiencing a cytokine storm in COVID-19. Moreover, some preclinical evidence suggests that the anti-inflammatory effects of DPP-4 may be more intense in elderly patients [35]. Taken as a whole, these data could explain why more beneficial effects of DPP-4i are observed in elderly patients with T2DM and COVID-19 than in younger populations.

We found that previous treatment with ARB, but not with ACEl, in elderly patients with T2DM hospitalized for COVID-19 was associated with a lower risk of all-cause mortality, a finding not previously reported in this population. The role of renin-angiotensin-aldosterone system (RAAS) inhibitors in the COVID-19 has not been fully characterized. Given that both ACEI and ARB induce up-regulation of ACE2 [36], it has been hypothesized that these drugs could augment susceptibility to and severity of SARS-CoV-2 infection [37]. However, data from observational studies indicate that use of RAAS inhibitors in patients with COVID-19 is safe $[17,38]$. A large meta-analysis which analyzed 28,872 patients and examined critical events and mortality data on patients prescribed ACEI and ARB found that their chronic use, especially among hypertensive patients with COVID-19, had beneficial effects [39]. In view of the foregoing, continuing ACEI and ARB treatment in COVID-19 patients has been recommended [40].

In spite of its upregulation of ACE2, the potential benefits of RAAS inhibitor treatment in COVID-19 could be explained through its enhancement of the ACE2/Ang1 - 7/Mas axis. It converts angiotensin II into Ang1 - 7, which has anti-inflammatory properties that preclude lung injury due to COVID-19 [41, 42]. Aging is associated with an upregulation of the angiotensin II proinflammatory pathway as well as a decrease in ACE2 levels and this likely predisposes elderly diabetic individuals to more severe COVID-19 disease [43].

Since ARB act on the final step of the RAAS system, blocking the AT1 receptor of angiotensin II, it has been postulated that they might be superior to ACEI in terms of improving COVID-19 prognosis [44]. In fact, better outcomes have been described in patients with COVID-19 and hypertension who receive ARB versus ACEI [11]. Until more evidence is available, it would be wise to prioritize the use of ARB over ACEl in this population.

This work also found that preadmission therapy with ASA was associated with increased in-hospital mortality in very old patients with diabetes hospitalized for COVID-19. One retrospective study concluded that ASA use may have protective effects on the lungs and reduce the need for mechanical ventilation, ICU admission, and in-hospital mortality in hospitalized COVID-19 patients [14]. This is likely related to the antithrombotic and anti-inflammatory properties of ASA. However, in that work, the mean age of ASAtreated patients was 62 years and only $55 \%$ had diabetes, so these results cannot be extrapolated to older diabetic patients.

The impact of ASA use on all-cause mortality in elderly patients is uncertain, as both favorable [45] and unfavorable [46] effects have been reported. In the ASPREE trial [46], which analyzed healthy patients $\geq$ 70 years of age, low-dose aspirin significantly increased the risk of major bleeding events and mortality. In light of this finding, the potential benefits of ASA use must be weighed against the risk of hemorrhage 
and other adverse effects in elderly diabetic individuals, especially those without prior cardiovascular disease [47].

Finally, preadmission therapy with statins showed a neutral effect on mortality in our population. It has been postulated that statins could have a potential role as an adjunct therapy in COVID-19 to mitigate endothelial dysfunction and dysregulated inflammation in patients with COVID-19 [48]. A possible antiviral effect of statins has also been postulated [49].

A meta-analysis [12] and two observational studies [13,50] -one of them in diabetic population [13]- have reported a significant reduction in mortality in patients with COVID-19 who received statins before admission. In another study, in-hospital statin use was linked to a reduced risk of mortality in individuals with COVID-19 [51]. Once again, the mean age of patients included in these studies was significantly younger than in our population, so this potential benefit may not exist in older patients.

Our study has several limitations. First, its observational design does not allow us to determine causal relationships. Additional randomized controlled trials are needed to evaluate confounding factors that were potentially overlooked in our study. Second, our study was conducted in very old patients with diabetes hospitalized with severe SARS-CoV-2 infection and thus its conclusions cannot be extrapolated to other populations with COVID-19. Third, we did not have data on the characteristics of patients' T2DM, such as glycemic control before hospitalization, duration of diabetes, blood glucose levels during hospitalization, or in-hospital anti-hyperglycemic management. Lastly, the data provided about at-home glucose-lowering drugs did not include information on treatment adherence or treatment duration.

\section{Conclusions}

We found important differences between cardiometabolic drugs and outcomes in older patients with T2DM hospitalized for COVID-19. Preadmission treatment with DPP-4i and ARB may reduce in-hospital mortality; other antidiabetic drugs, ACEI and statins seem to have a neutral effect; and ASA may be associated with excess mortality. These findings, which could have important clinical implications, must be confirmed in further controlled trials.

\section{Abbreviations}

ACEl: angiotensin-converting enzyme inhibitors

AOR: adjusted odds ratios

ARB: angiotensin receptor blockers

ASA: acetylsalicylic acid

COVID-19: coronavirus disease-2019 
DPP-4: dipeptidyl peptidase-4

DPP-4i: dipeptidyl peptidase-4 inhibitors

eGFR: estimated glomerular filtration rate

GLP-1 ra: glucagon-like peptide-1 receptor agonist

IQR: interquartile ranges

qSOFA: quick sequential organ failure assessment

ROC: receiver operating characteristic

RT-PCR: reverse transcription polymerase chain reaction

SARS-CoV-2: severe acute respiratory syndrome coronavirus 2

SGLT-2i: sodium-glucose cotransporter 2 inhibitors

SEMI (for its initials in Spanish): Spanish Society of Internal Medicine

T2DM: type 2 diabetes mellitus

\section{Declarations}

\section{Ethics approval and consent to participate}

All patients gave their informed consent. When there were biosafety concerns and/or when the patient had already been discharged, verbal informed consent was requested and noted on the medical record. Data confidentiality and patient anonymity were maintained at all times, in accordance with Spanish regulations on observational studies. This study was carried out in accordance with the Declaration of Helsinki and was approved by the Institutional Research Ethics Committee of Málaga on March 27, 2020 (Ethics Committe code: SEMI-COVID-19 27-03-20), as per the guidelines of the Spanish Agency of Medicines and Medical Products.

\section{Consent for publication}

Not applicable.

\section{Availability of data and materials}

All data generated or analysed during this study are included in this published article.

\section{Competing interest}


The authors declare that they have no competing interests.

\section{Funding}

This research received no specific grant from any funding agency in the public, commercial or not-forprofit sectors.

\section{Authors' contributions}

JMRR contributed to the conception, design of the work the acquisition, interpretation of data, writingoriginal draft preparation, writing-review and editing, and supervision. FJCS, SJC, MDSB, JBF, MPA, CAC,

MBC, MMB, IFM, AGG, FNR, CTA, GMN, AGN, AHM, GMGG, JNAP, VHG, LCG, PCC, HMM, and JMCR made contributions to the acquisition of data and revised the work. LMPB contributed to interpretation of data, writing-review and editing, and supervision. RGH was a major contributor in interpretation of data, writingoriginal draft preparation, writing-review and editing, and supervision. All authors read and approved the final manuscript.

\section{Acknowledgments}

We thank Claire Alexandra Conrad for her help with the final English-language version and the SEMICOVID-19 Registry Coordinating Center, S\&H Medical Science Service, for their quality control data, logistic and administrative support.

\section{References}

1. Docherty AB, Harrison EM, Green CA, Hardwick HE, Pius R, Norman L, et al; ISARIC4C investigators. Features of 20133 UK patients in hospital with covid-19 using the ISARIC WHO Clinical Characterisation Protocol: prospective observational cohort study. BMJ. 2020;369:m1985.

2. Petrilli CM, Jones SA, Yang J, Rajagopalan H, O'Donnell L, Chernyak Y, et al. Factors associated with hospital admission and critical illness among 5279 people with coronavirus disease 2019 in New York City: prospective cohort study. BMJ. 2020;369:m1966.

3. Iaccarino G, Grassi G, Borghi C, Ferri C, Salvetti M, Volpe M; SARS-RAS Investigators. Age and Multimorbidity Predict Death Among COVID-19 Patients: Results of the SARS-RAS Study of the Italian Society of Hypertension. Hypertension. 2020;76:366-72.

4. Ramos-Rincon JM, Buonaiuto V, Ricci M, Martín-Carmona J, Paredes-Ruíz D, Calderón-Moreno M, et al; SEMI-COVID-19 Network. Clinical characteristics and risk factors for mortality in very old patients hospitalized with COVID-19 in Spain. J Gerontol A Biol Sci Med Sci. 2020:glaa243.

5. Yang J, Zheng Y, Gou X, Pu K, Chen Z, Guo Q, et al. Prevalence of comorbidities and its effects in patients infected with SARS-CoV-2: a systematic review and meta-analysis. Int $J$ Infect Dis. 2020;94:91-5. 
6. Casas Rojo JM, Antón Santos JM, Millán Núñez-Cortés J, Lumbreras-Bermejo C, Ramos-Rincón JM, Roy-Vallejo E, et al. Clinical characteristics of patients hospitalized with COVID-19 in Spain: results from the SEMI-COVID-19 Registry. Rev Clin Esp. 2020;220:480-94.

7. Fadini GP, Morieri ML, Longato E, Avogaro A. Prevalence and impact of diabetes among people infected with SARS-CoV-2. J Endocrinol Invest. 2020;43:867-9.

8. Apicella M, Campopiano MC, Mantuano M, Mazoni L, Coppelli A, Del Prato S. COVID-19 in people with diabetes: understanding the reasons for worse outcomes. Lancet Diabetes Endocrinol. 2020;8:782-92.

9. Lamontagne F, Agoritsas T, Macdonald H, Leo YS, Diaz J, Agarwal A, et al. A living WHO guideline on drugs for covid-19. BMJ. 2020;370:m3379.

10. Baral $R$, White $M$, Vassiliou VS. Effect of renin-angiotensin-aldosterone system inhibitors in patients with COVID-19: a systematic review and meta-analysis of 28,872 patients. Curr Atheroscler Rep. 2020;22:61.

11. Rodilla E, Saura A, Jiménez I, Mendizábal A, Pineda-Cantero A, Lorenzo-Hernández E, et al. Association of hypertension with all-cause mortality among hospitalized patients with COVID-19. J Clin Med. 2020;9:E3136.

12. Kow CS, Hasan SS. Meta-analysis of effect of statins in patients with COVID-19. Am J Cardiol. 2020;134:153-5.

13. Saeed O, Castagna F, Agalliu I, Xue X, Patel SR, Rochlani Y, et al. Statin Use and In-Hospital Mortality in Diabetics with COVID-19. J Am Heart Assoc. 2020:e018475.

14. Chow JH, Khanna AK, Kethireddy S, Yamane D, Levine A, Jackson AM, et al. Aspirin use is associated with decreased mechanical ventilation, ICU admission, and in-hospital mortality in hospitalized patients with COVID-19. Anesth Analg. 2020 Oct 21.

15. Solerte SB, D'Addio F, Trevisan R, Lovati E, Rossi A, Pastore I, et al. Sitagliptin treatment at the time of hospitalization was associated with reduced mortality in patients with type 2 diabetes and COVID-19: a multicenter, case-control, retrospective, observational study. Diabetes Care. 2020:dc201521.

16. Kow CS, Hasan SS. Mortality risk with preadmission metformin use in patients with COVID-19 and diabetes: A meta-analysis. J Med Virol. 2020 Sep 9.

17. Fosbøl EL, Butt JH, Østergaard L, Andersson C, Selmer C, Kragholm K, et al. Association of angiotensin-converting enzyme inhibitor or angiotensin receptor blocker use with COVID-19 diagnosis and mortality. JAMA. 2020;324:168-77.

18. Bramante C, Ingraham N, Murray T, Marmor S, Hoversten S, Gronski J, et al. Observational study of metformin and risk of mortality in patients hospitalized with Covid-19. medRxiv. 2020:2020.06.19.20135095.

19. Pérez-Belmonte LM, Torres-Peña JD, López-Carmona MD, Ayala-Gutiérrez MM, Fuentes-Jiménez F, Jorge-Huerta L, et al; for the SEMI-COVID-19 Network. Mortality and other adverse outcomes in patients with type 2 diabetes mellitus admitted for COVID-19 in association with glucose-lowering drugs: a nationwide cohort study. BMC Medicine. 2020;18:359. 
20. Chen Y, Yang D, Cheng B, Chen J, Peng A, Yang C, et al. Clinical characteristics and outcomes of patients with diabetes and COVID-19 in association with glucose-lowering medication. Diabetes Care. 2020;43:1399-407.

21. Yu B, Li C, Sun Y, Wang DW. Insulin treatment is associated with increased mortality in patients with COVID-19 and type 2 diabetes. Cell Metab. 2020;S1550-4131(20)30647-1.

22. Rhee SY, Lee J, Nam H, Kyoung DS, Kim DJ. Effects of a DPP-4 inhibitor and RAS blockade on clinical outcomes of patients with diabetes and COVID-19. medRxiv. 2020;05.20.20108555

23. Drucker DJ. Coronavirus infections and type 2 diabetes-shared pathways with therapeutic implications. Endocr Rev. 2020;41:bnaa011

24. Solerte SB, Di Sabatino A, Galli M, Fiorina P. Dipeptidyl peptidase-4 (DPP4) inhibition in COVID-19. Acta Diabetol. 2020;57:779-83

25. Bornstein SR, Rubino F, Khunti K, Mingrone G, Hopkins D, Birkenfeld AL, et al. Practical recommendations for the management of diabetes in patients with COVID-19. Lancet Diabetes Endocrinol. 2020;8:546-50

26. Makdissi A, Ghanim H, Vora M, Green K, Abuaysheh S, Chaudhuri A, et al. Sitagliptin exerts an antinflammatory action. J Clin Endocrinol Metab. 2012;97:3333-41.

27. Pinheiro MM, Stoppa CL, Valduga CJ, Okuyama CE, Gorjão R, Pereira RMS, et al. Sitagliptin inhibit human lymphocytes proliferation and Th1/Th17 differentiation in vitro. Eur J Pharm Sci. 2017;100:17-24.

28. Cunha LL, Perazzio SF, Azzi J, Cravedi P, Riella LV. Remodeling of the immune response with aging: immunosenescence and its potential impact on COVID-19 immune response. Front Immunol. 2020;11:1748.

29. Yan R, Zhang Y, Li Y, Xia L, Guo Y, Zhou Q. Structural basis for the recognition of SARS-CoV-2 by fulllength human ACE2. Science. 2020;367:1444-8

30. Li Y, Zhang Z, Yang L, Lian X, Xie Y, Li S, et al. The MERS-CoV receptor DPP4 as a candidate binding target of the SARS-CoV-2 spike. iScience 2020;23:101400.

31. lacobellis G. COVID-19 and diabetes: can DPP4 inhibition play a role? Diabetes Res Clin Pract. 2020;162:108125.

32. Strollo R, Pozzilli P. DPP4 inhibition: preventing SARS-CoV-2 infection and/or progression of COVID19?. Diabetes Metab Res Rev. 2020;e3330.

33. Detel D, Baticic L, Varljen J. The influence of age on intestinal dipeptidyl peptidase IV (DPP IV/CD26), disaccharidases, and alkaline phosphatase enzyme activity in C57BL/6 mice. Exp Aging Res. 2008;34:49-62.

34. Kim KM, Noh JH, Bodogai M, Martindale JL, Yang X, Indig FE, et al. Identification of senescent cell surface targetable protein DPP4. Genes Dev. 2017;31:1529-34.

35. Omar BA, Vikman J, Winzell MS, Voss U, Ekblad E, Foley JE, et al. Enhanced beta cell function and anti-inflammatory effect after chronic treatment with the dipeptidyl peptidase-4 inhibitor vildagliptin 
in an advanced-aged diet-induced obesity mouse model. Diabetologia. 2013;56:1752-60.

36. Furuhashi M, Moniwa N, Mita T, Fuseya T, Ishimura S, Ohno K, et al. Urinary angiotensin-converting enzyme 2 in hypertensive patients may be increased by olmesartan, an angiotensin II receptor blocker. Am J Hypertens. 2015;28:15-21.

37. Fang L, Karakiulakis $G$, Roth M. Are patients with hypertension and diabetes mellitus at increased risk for COVID-19 infection?. Lancet Respir Med. 2020;8:e21.

38. Mancia G, Rea F, Ludergnani M, Apolone G, Corrao G. Renin-Angiotensin-Aldosterone System Blockers and the risk of Covid-19. N Engl J Med. 2020;382:2431-40.

39. Baral R, White M, Vassiliou VS. Effect of Renin-Angiotensin-Aldosterone System inhibitors in patients with COVID-19: a systematic review and meta-analysis of 28,872 patients. Curr Atheroscler Rep. 2020;22:61

40. American College of Cardiology. HFSA/ACC/AHA statement addresses concerns reusing RAAS antagonists in COVID-19.March 17, 2020 (https://www.acc.org/latestin-cardiology/ articles/2020/03/17/ 08/59/ hfsa-accahastatementaddresses-concernsreusingraasantagonists-incovid19) (European Society of Cardiology. Position statement of the ESC Council on Hypertension on ACE-inhibitors and angiotensin receptor blockers. March 13, 2020 (https://www.escardio.org/Councils/Council-onHypertension-(CHT)/News/position-statement-of-theesc-council-on-hypertension-on-ace-inhibitors-and-ang

41. Jia H. Pulmonary angiotensin-converting enzyme 2 (ACE2) and inflammatory lung disease, Shock. 2016;46:239-48.

42. Kuba K, Imai Y, Rao S, Gao H, Guo F, Guan B, et al. A crucial role of angiotensin converting enzyme 2 (ACE2) in SARS coronavirus-induced lung injury. Nat Med. 2005;11:875-9.

43. AlGhatrif M, Cingolani O, Lakatta EG. The dilemma of coronavirus disease 2019 , aging, and cardiovascular disease: insights from cardiovascular aging science. JAMA Cardiol. 2020;5:747-8.

44. Saavedra JM. Angiotensin receptor blockers and COVID-19, Pharmacol Res. 2020;156:104832.

45. Loomans-Kropp HA, Pinsky P, Cao Y, Chan AT, Umar A. Association of aspirin use with mortality risk among older adult participants in the Prostate, Lung, Colorectal, and Ovarian Cancer Screening Trial. JAMA Netw Open. 2019;2:e1916729.

46. McNeil JJ, Nelson MR, Woods RL, Lockery JE, Wolfe R, Reid CM, et al; ASPREE Investigator Group. Effect of aspirin on all-cause mortality in the healthy elderly. N Engl J Med. 2018;379:1519-28

47. Patel NJ, Baliga RR. Role of aspirin for primary prevention in persons with diabetes mellitus and in the elderly. Cardiol Rep. 2020;22:48

48. Lee KCH, Sewa DW, Phua GC. Potential role of statins in COVID-19. Int J Infect Dis. 2020;96:615-7.

49. Reiner Z, Hatamipour M, Banach M, Pirro M, Al Rasadi K, Jamialahmadi T, et al. Statins and the COVID-19 main protease: in silico evidence on direct interaction. Arch Med Sci. 2020;16:490-6.

50. Daniels LB, Sitapati AM, Zhang J, Zou J, Bui QM, Ren J, et al. Relation of statin use prior to admission to severity and recovery among COVID-19 inpatients. Am J Cardiol. 2020;136:149-55. 
51. Zhang X-J, Qin J-J, Cheng X, Shen L, Zhao Y-C, Yuan Y, et al. In-hospital use of statins is associated with a reduced risk of mortality among individuals with COVID-19. Cell Metab. 2020;32:176-87.

\section{Tables}

Table 1. Baseline clinical characteristics, clinical presentation, and laboratory data of patients ${ }^{3} 80$ years with type 2 diabetes mellitus hospitalized due to COVID-19 grouped by non-survivors and survivors. 


\begin{tabular}{|c|c|c|c|c|}
\hline & Missing & $\begin{array}{l}\text { Non-survivors } \\
(n=385)\end{array}$ & $\begin{array}{l}\text { Survivors } \\
(n=405)\end{array}$ & $\begin{array}{l}\mathrm{p}- \\
\text { value }\end{array}$ \\
\hline Age, years & & $86(82.7-88.9)$ & $\begin{array}{l}85.8(82.7- \\
88.9)\end{array}$ & 0.477 \\
\hline Sex, female & 2 & $166(43.2)$ & $206(51.0)$ & 0.029 \\
\hline Acquisition & 5 & & & 0.124 \\
\hline Community & & $266(69.8)$ & $281(69.6)$ & \\
\hline Nosocomial & & $41(10.8)$ & $29(7.2)$ & \\
\hline Nursing home & & $74(19.4)$ & $94(23.3)$ & \\
\hline \multicolumn{5}{|l|}{ Comorbidities and dependence } \\
\hline Moderate-severe functional dependence & 10 & $219(57.6)$ & $179(44.8)$ & $<0.001$ \\
\hline $\mathrm{CCl}$ & 30 & $7(6-9)$ & $7(6-8)$ & 0.110 \\
\hline Hypertension & 1 & $319(82.6)$ & $347(85.9)$ & 0.204 \\
\hline Dyslipidemia & 0 & $250(64.9)$ & $272(67.2)$ & 0.509 \\
\hline Dementia & 1 & $144(37.4)$ & $122(30.2)$ & 0.032 \\
\hline Atrial fibrillation & 1 & $111(28.8)$ & $111(27.5)$ & 0.672 \\
\hline Coronary artery disease & 3 & $80(20.8)$ & $70(17.4)$ & 0.213 \\
\hline Cerebrovascular disease & 4 & $82(21.4)$ & $71(17.7)$ & 0.192 \\
\hline Peripheral vascular disease & 2 & $53(13.8)$ & $42(10.4)$ & 0.150 \\
\hline Heart failure & 4 & $83(21.6)$ & $75(18.7)$ & 0.301 \\
\hline Chronic obstructive pulmonary disease $\mathrm{F}^{\mathrm{F}}$ & 4 & $65(16.9)$ & 75 (18.7) & 0.526 \\
\hline Obesity FF & 94 & $74(22.2)$ & $66(18.2)$ & 0.184 \\
\hline Malignancy FFF & 4 & $63(16.4)$ & $43(10.7)$ & 0.118 \\
\hline $\begin{array}{l}\text { Moderate-to-severe chronic kidney } \\
\text { disease }\end{array}$ & 5 & $73(19.1)$ & $63(15.7)$ & 0.210 \\
\hline \multicolumn{5}{|l|}{ Clinical presentation } \\
\hline Dyspnea & 2 & $270(70.3)$ & $212(52.5)$ & $<0.001$ \\
\hline Oxygen saturation $<90 \%$ & 18 & $143(38.1)$ & $55(13.9)$ & $<0.001$ \\
\hline Temperature ${ }^{3} 37.8^{\circ} \mathrm{C}$ & 49 & $95(26.3)$ & $59(15.5)$ & $<0.001$ \\
\hline Tachycardia (>100 beats per minute) & 27 & $98(26.4)$ & $62(15.8)$ & $<0.001$ \\
\hline
\end{tabular}




\begin{tabular}{|c|c|c|c|c|}
\hline qSOFA score ${ }^{3} 2$ & 0 & $122(31.7)$ & $52(12.8)$ & $<0.001$ \\
\hline \multicolumn{5}{|l|}{ Laboratory data } \\
\hline Leukocytes $\left(10^{3} / \mathrm{mL}\right)$ & 11 & $\begin{array}{l}7.82(5.82- \\
10.81)\end{array}$ & $\begin{array}{l}6.73(0.50- \\
8.72)\end{array}$ & $<0.001$ \\
\hline Neutrophils $\left(10^{3} / \mathrm{mL}\right)$ & 16 & $6.39(4.64-9.08)$ & $\begin{array}{l}4.85(3.40- \\
6.88)\end{array}$ & $<0.001$ \\
\hline Lymphocytes $\left(10^{3} / \mathrm{mL}\right)$ & 14 & $0.80(0.50-1.21)$ & $\begin{array}{l}0.96(0.70- \\
1.30)\end{array}$ & $<0.001$ \\
\hline Hemoglobin (g/dL) & 11 & $12.9(11.3-14.1)$ & $\begin{array}{l}12.7(11.3- \\
13.8)\end{array}$ & 0.342 \\
\hline Platelet count $\left(10^{3} / \mathrm{mL}\right)$ & 11 & $186(143-245)$ & $186(127-246)$ & 0.642 \\
\hline Glucose (mg/dL) & 38 & $176(139-237)$ & $146(116-203)$ & $<0.001$ \\
\hline eGFR (ml/min/1.73m²) & 18 & $\begin{array}{l}41.35(27.9- \\
60.3)\end{array}$ & $\begin{array}{l}51.7(35.8- \\
69.7)\end{array}$ & $<0.001$ \\
\hline Lactate dehydrogenase $(\mathrm{U} / \mathrm{L})$ & 157 & $380(288-524)$ & $284(219-373)$ & $<0.001$ \\
\hline AST (U/L) & 223 & $36(25-57)$ & $27(20-39)$ & $<0.001$ \\
\hline $\operatorname{ALT}(\mathrm{U} / \mathrm{L})$ & 99 & $25.5(16-36)$ & $20(14-29)$ & 0.010 \\
\hline C-reactive protein $(\mathrm{mg} / \mathrm{dL})$ & 38 & $117(52-198)$ & $50(19-111)$ & $<0.001$ \\
\hline Venous lactate (mmol/L) & 412 & $2.0(1.4-3.0)$ & $1.6(1.2-2.50)$ & 0.002 \\
\hline Procalcitonin (ng/mL) & 407 & $0.23(0.12-0.65)$ & $\begin{array}{l}0.12(0.07- \\
0.22)\end{array}$ & $<0.001$ \\
\hline Interleukin-6 (pg/mL) & 719 & $47.3(25.2-100)$ & $20.8(9.0-65.1)$ & 0.015 \\
\hline D-dimer (ng/mL) & 404 & $\begin{array}{l}1310(713- \\
3270)\end{array}$ & $\begin{array}{l}1026(586- \\
2105)\end{array}$ & 0.010 \\
\hline Ferritin /mg/L & 519 & $582(285-1287)$ & 359 (179-707) & $<0.001$ \\
\hline $\mathrm{pH}$ & 341 & $7.43(7.39-7.47)$ & $\begin{array}{l}7.44(7.39- \\
7.47)\end{array}$ & 0.358 \\
\hline $\mathrm{pCO}_{2}(\mathrm{mmHg})$ & 351 & $35.8(30.8-41.0)$ & $\begin{array}{l}35.8(31.2- \\
41.8)\end{array}$ & 0.265 \\
\hline $\mathrm{pO}_{2}(\mathrm{mmHg})$ & 364 & $58.5(51.0-69.5)$ & $\begin{array}{l}68.0(57.0- \\
80.5)\end{array}$ & $<0.001$ \\
\hline $\mathrm{pO}_{2} / \mathrm{FiO}_{2}$ ratio & 383 & $247(184-296)$ & $290(248-342)$ & $<0.001$ \\
\hline
\end{tabular}

Values are shown as medians and interquartile ranges and as absolute values and percentages, respectively. Values were considered to be statistically significant when $p<0.05$. 
${ }^{F}$ Chronic pulmonary disease includes chronic obstructive pulmonary disease and/or asthma.

FFObesity: body mass index ${ }^{3} 30 \mathrm{~kg} / \mathrm{m}^{2}$.

${ }^{\mathrm{FFF}}$ Malignancy includes solid tumors or hematologic neoplasms.

CCI: Charlson comorbidity index; IQR: interquartile range; qSOFA: quick sequential organ failure assessment.

Table 2. Preadmission cardiometabolic medications of patients ${ }^{3} 80$ years with type 2 diabetes mellitus hospitalized due to COVID-19 grouped by non-survivors and survivors.

\begin{tabular}{|lllll|}
\hline & Missing & $\begin{array}{c}\text { Non-survivors } \\
(\mathbf{n = 3 8 5})\end{array}$ & $\begin{array}{l}\text { Survivors } \\
(\mathbf{n}=405)\end{array}$ & p-value \\
\hline Antidiabetic drugs & 1 & $206(53.5)$ & $214(53.0)$ & 0.880 \\
\hline Metformin & 15 & $110(28.9)$ & $143(36.2)$ & 0.031 \\
\hline DPP-4i & 14 & $103(27.2)$ & $108(27.2)$ & 0.993 \\
\hline Insulin & 13 & $17(4.5)$ & $15(3.8)$ & 0.626 \\
\hline SGLT-2i & 13 & $11(2.9)$ & $13(3.3)$ & 0.755 \\
\hline GLP-1ra & & & & \\
\hline Lipid-lowering drugs & 7 & $188(49.2)$ & $227(56.6)$ & 0.038 \\
\hline Statin & & & & \\
\hline Antihypertensive drugs & & $44(11.6)$ & $52(13.1)$ & 0.538 \\
\hline ACEI & 15 & $27(7.1)$ & $79(19.8)$ & $<0.001$ \\
\hline ARB & 12 & & & \\
\hline Antiaggregant drugs & & $132(34.6)$ & $132(29.6)$ & 0.131 \\
\hline ASA & 7 & &
\end{tabular}

Values are shown as absolute values and percentages. Values were considered to be statistically significant when $\mathrm{p}<0.05$.

ACEl: angiotensin-converting enzyme inhibitor; ARB: angiotensin receptor blocker; ASA: acetylsalicylic acid; DDP-4i: Dipeptidyl peptidase-4 inhibitor; GLP-1 ra: Glucagon-like peptide-1 receptor agonist; SGLT-2i: sodium-glucose linked transporter-2 inhibitor. 
Table 3. Associations between preadmission cardiometabolic drugs and in-hospital mortality in patients $\geq 80$ years with type 2 diabetes mellitus hospitalized due to COVID-19

\begin{tabular}{|lll|}
\hline & AOR $(95 \% \mathrm{Cl})$ & $\mathrm{p}$-value \\
\hline Metformin & $0.976(0.639-1.788)$ & 0.782 \\
\hline DPP-4i & $0.502(0.309-0.815)$ & 0.005 \\
\hline Insulin & $1.308(0.679-2.476)$ & 0.579 \\
\hline SGLT-2i & $0.812(0.755-1.988)$ & 0.401 \\
\hline GLP-1ra & $0.912(0.501-1.896)$ & 0.521 \\
\hline ASA & $1.761(1.092-2.842)$ & 0.020 \\
\hline ACEI & $1.048(0.841-1.991)$ & 0.186 \\
\hline ARB & $0.454(0.274-0.759)$ & 0.003 \\
\hline Statins & $0.917(0.723-1.978)$ & 0.335 \\
\hline Hosmer-Lemeshow test & & 0.144 \\
\hline AUC & $0.788(0.750-0.826)$ & 0.001 \\
\hline
\end{tabular}

A multivariate logistic regression analysis were performed to assess the association between preadmission cardiometabolic therapy and in-hospital mortality. The regression analysis values were expressed as adjusted odds ratios with a $95 \%$ confidence interval. In order to select the variables, the forward selection Wald statistic was used. Discrimination of the fitted logistic model was assessed via a receiver operating characteristic (ROC) curve. The Hosmer-Lemeshow test for logistic regression was used to determine the model's goodness of fit. Values were considered to be statistically significant when $p<0.05$.

ACEl: angiotensin-converting enzyme inhibitor; AOR: adjusted odds ratios; ARB: angiotensin receptor blocker; ASA: acetylsalicylic acid; Cl: confidence interval; DDP-4i: Dipeptidyl peptidase-4 inhibitor; eGFR: estimated glomerular filtration rate; GLP-1 ra: glucagon-like peptide-1 receptor agonist; qSOFA: quick sequential organ failure assessment; SGLT-2i: sodium-glucose cotransporter 2 inhibitors

\section{Figures}




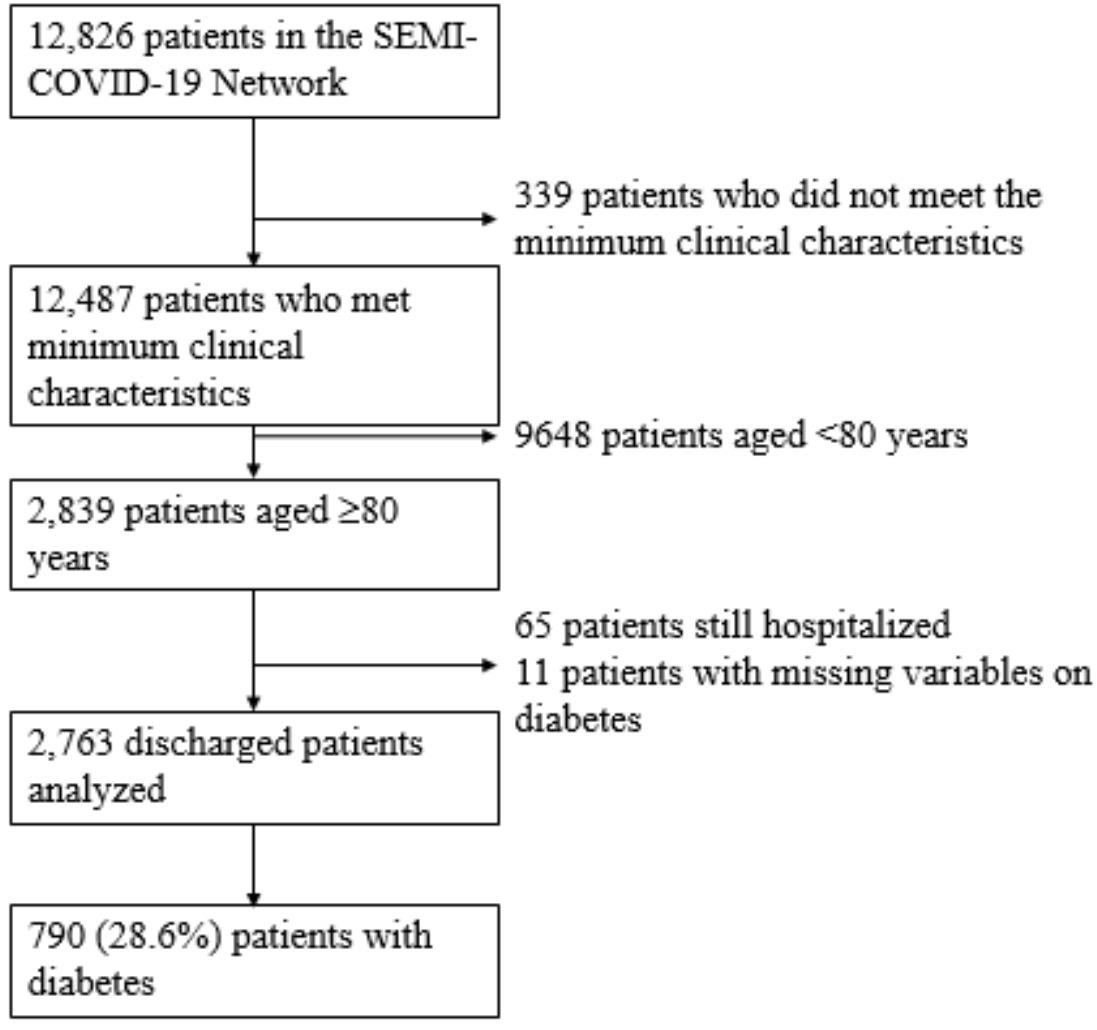

Figure 1

Patient inclusion flow chart. COVID-19: coronavirus disease-2019; SEMI (for its initials in Spanish): Spanish Society of Internal Medicine

\section{Supplementary Files}

This is a list of supplementary files associated with this preprint. Click to download.

- Appendixauthors.docx 